This item was submitted to Loughborough's Research Repository by the author.

Items in Figshare are protected by copyright, with all rights reserved, unless otherwise indicated.

\title{
Improved modelling capabilities of the airflow within turbine case cooling systems using smart porous media
}

\section{PLEASE CITE THE PUBLISHED VERSION}

https://doi.org/10.1115/1.4041933

\section{PUBLISHER}

ASME (The American Society of Mechanical Engineers) @ Rolls-Royce plc

\section{VERSION}

AM (Accepted Manuscript)

\section{PUBLISHER STATEMENT}

This paper was accepted for publication in the journal Journal of Engineering for Gas Turbines and Power and the definitive published version is available at https://doi.org/10.1115/1.4041933.

\section{LICENCE}

CC BY 4.0

\section{REPOSITORY RECORD}

Li, Yanling, Duncan Walker, and John Irving. 2018. "Improved Modelling Capabilities of the Airflow Within Turbine Case Cooling Systems Using Smart Porous Media”. Loughborough University. https://hdl.handle.net/2134/35725. 


\section{American Society of Mechanical Engineers}

SETTING THE STANDARD

\section{ASME Accepted Manuscript Repository}

\section{Institutional Repository Cover Sheet}

ASME Paper Title:

Improved Modeling Capabilities of the Airflow Within Turbine Case Cooling Systems

Using Smart Porous Media

Yanling Li, A. Duncan Walker and John Irving

Authors:

Journal of Engineering for Gas Turbines and Power

ASME Journal Title:

Volume/Issue

Date of Publication (VOR* Online) Nov, 22 $141(5)$ 2018

http://gasturbinespower. asmedigitalcollection. asme.org/article. aspx?articleid=2714571 ASME Digital Collection URL:

DOI:

*VOR (version of record) 


\title{
Improved Modelling Capabilities of The Airflow Within Turbine Case Cooling Systems Using Smart Porous Media
}

\author{
Yanling Li \\ Loughborough University \\ Department of Aeronautical and Automotive Engineering \\ Loughborough University \\ Loughborough, LE11 3TU, UK \\ y.li3@lboro.ac.uk \\ A Duncan Walker ${ }^{1}$ \\ Loughborough University \\ Department of Aeronautical and Automotive Engineering \\ Loughborough University \\ Loughborough, LE11 3TU, UK \\ a.d.walker@lboro.ac.uk \\ John Irving \\ Rolls-Royce plc \\ Rolls-Royce plc \\ PO Box 31, Moor Lane, Derby, DE24 8BJ, UK \\ John.Irving2@Rolls-Royce.com
}

\begin{abstract}
Impingement cooling is commonly employed in gas turbines to control the turbine tip clearance. During the design phase, Computational Fluid Dynamics is an effective way of evaluating such systems but for most Turbine Case Cooling (TCC) systems resolving the small scale and large number of cooling holes is impractical at the preliminary design phase. This paper presents an alternative approach for predicting aerodynamic performance of TCC systems using a "smart" porous media to replace regions of cooling holes. Numerically (CFD) defined correlations have been developed, which account for geometry and local flow field, to define the porous media loss coefficient. These are coded as a user defined function allowing
\end{abstract}

\footnotetext{
${ }^{1}$ Corresponding author
} 
the loss to vary, within the calculation, as a function of the predicted flow and hence produce a spatial variation of mass flow matching that of the cooling holes. The methodology has been tested on various geometrical configurations representative of current TCC systems and compared to full cooling hole models. The method was shown to achieve good overall agreement whilst significantly reducing both the mesh count and the computational time to a practical level.

Key words: aerodynamics, CFD, gas turbines, turbine case cooling (TCC), impingement cooling holes. 


\section{INTRODUCTION}

In modern aero-engines, control of the over-tip leakage flow in turbines is crucial in reducing secondary flow losses and hence improving specific fuel consumption. Various tip or shroud geometries have been utilized in an attempt to minimize these losses but in all cases the tip clearance varies notably through the flight cycle due to the differential expansion of the rotor and the casing under the action of centrifugal and thermal loads. Therefore, it is common practice to employ a Turbine Case Cooling (TCC) system to control the thermal expansion of the casing and hence actively manage the tip clearance. See, for example, Lattime and Steinetz [1, 2] and Melcher and Kypuros [3]. A typical TCC system, as shown in Fig. 1, consists of an off-take, an inlet duct, a butterfly valve(s) and air transfer boxes connected to a set of circumferential manifolds. These feed several arrays of impingement cooling holes which deliver the cooling air to the surface of the turbine casing. However, design of TCC systems is, in practice, challenging. TCC systems are complex and comprise of many interacting sub-systems all with different aero thermal and mechanical constraints.

The aim of the TCC systems is to optimize tip clearance across different engine operating conditions [4] and around the casing circumference. To achieve this a key requirement is to provide a near-uniform delivery of cooling air to the turbine casing. The cooling flow is commonly extracted from the bypass duct; directed towards the turbine casing through an inlet duct; the mass flow rate of the cooling flow is controlled by the valve and the cooling flow is then delivered to the turbine casing through the manifold (Fig. 1). According to Miller [5], one of the main factors affecting the 
uniformity of flow distribution of the impingement cooling holes in the manifold is the loss ratio. This can be expressed as either (i) the ratio of the inlet dynamic pressure of the manifold to the losses across the impingement cooling holes or (ii) the ratio of the total impingement cooling hole area to the manifold cross-sectional area. Ideally at the design stage the loss ratio should not be greater than 1 as this results in poor uniformity of the flow distribution resulted as reported by Miller [5] and illustrated in Fig. 2. Theoretically, the required flow distribution could be achieved by adjusting total impingement cooling hole areas, manifold areas and loss coefficients. Another parameter that affects the flow distribution of impingement cooling holes is the length of the manifold. Miller [5] (Fig. 2) reported that with a low loss ratio, less than 0.5 , the uniformity of the flow distribution is fairly good regardless of the length of the manifold. However, with a medium to high loss ratio the uniformity begins to vary notably.

Developing TCC systems through the use of an experimental campaign is time consuming, expensive and yields limited data due to the difficulties of installing suitable instrumentation. Use of existing correlations and in-house experience is limited by different engine architectures and requirements leading to varying design styles being employed. Furthermore, during engine development it is common to undertake several iterations as, for example, cooling flow budgets change. To save development costs, or due to space constraints, certain features, such as the manifold cross-sectional area, are often fixed at an early stage. As other parameters change, this can often compromise the final design. It is therefore attractive to employ Computational Fluid Dynamics (CFD) to support the design process, particularly in the early phases. However, the complex 
nature of the geometry and existence of multiple small features such as the impingement cooling holes make generating and running a high fidelity CFD model too computationally intensive to be of practical use. The major difficulty for CFD simulations to investigate this type of problem is the large disparity in scales both in terms of the geometry and the flow topology. The turbine case is of order one to two meters diameter whilst the several thousand impingement cooling holes are typically of order one millimeter in diameter. The challenge is how to capture the general flow within the whole TCC system without the need to model the individual impingement cooling holes.

To overcome the problem, this paper describes the development of a numerical methodology which allows the impingement cooling holes to be replaced by porous media zones which mathematically simulate the same pressure drop (see Fig. 3). The main advantage of this approach is that it simplifies the computational domain and reduces computational cost to such a level that CFD can be used as a practical design tool. This type of porous media approach has been used in several other fields including the modelling of catalytic converters, heat exchangers, concrete flow and fuel injectors (see [6 - 12]). There have also been multiple studies on impingement flows such as flow through perforated plates [13], flow through impingement cooling holes employed as film cooling in turbine blades [14-16], combustor liners [17-18] and TCC systems [4, 19]. However, these studies tend to look at the local performance of, for example, the impingement cooling mechanism. Therefore, they modelled the local geometry in detail but overlook the performance of the whole integrated system. This is particularly important in TCC systems where upstream components (off-takes, valves, junctions etc.) 
will play a major role in determining the quality of the flow delivered to the impingement cooling holes. The current work aims to address this and develop a robust methodology for replacing the small-scale impingement cooling holes with porous media thus facilitating the modelling of the whole upstream TTC system. The paper presents a theoretical derivation of this porous media approach followed by an assessment of the effect of various global geometrical parameters. Throughout, where feasible, the results are compared to, and validated against, cases with the corresponding fully featured geometry which includes the impingement cooling holes. 


\section{POROUS MEDIA METHODOLOGY}

\section{Theoretical Derivation}

In the current work, the commercial CFD code ANSYS Fluent has been used for all predictions. All solutions were converged based on second order accuracy utilizing a RANS approximation, a pressure-based solver with $k-\omega$ SST turbulence closure which is commonly used for predicting impingement cooling hole problems in the literature (e.g. Andreini et al. [4]). Convergence was judged by monitoring the residuals within the solutions and the flow parameters at the inlet of the domain. All cases with impingement cooling hole features utilized a compressible solver as the flow in the holes exceeds a Mach number of 0.3. However, in the porous media cases the flow never reaches velocities associated with compressibility and as such those cases employed an incompressible solver; the inlet Mach number is typically around 0.1 . The typical mesh density used had a node spacing in the order of $0.5-1.0 \mathrm{~mm}$ with significantly increased resolution applied inside and near the impingement cooling hole regions. The boundary conditions used were based on typical cruise conditions for a large civil turbofan with uniform pressures applied at the inlet and outlet. For simplicity in developing the porous media methodology all simulations were assumed to be isothermal and heat transfer was not considered. It will be shown later that this is a valid assumption and the effects of heat transfer are small, and arguably negligible, when compared to the effects of geometry. However, the methodology can be easily adapted to account for the effects heat transfer. Eq (1) shows that the porous media source term accounts for changes in density and velocity resulting from heat 
transfer. However, this would require prior knowledge of the heat loads on the turbine casing which is generally not available at the preliminary design stage for which this method is intended. Additionally, this would probably also require a conjugate heat transfer solution to capture the two-way coupled heating-cooling effects between the air and the metal casing. Although possible this would add significant numerical expense which will somewhat negate the aim of this methodology providing a rapid, numerically fast design tool.

Porous media is commonly modelled as a volume in many CFD codes by adding a source term in the momentum equations which replicates the pressure loss across the media [20]. The source term normally consists of a viscous loss term and an inertial term which need to be defined by the user. According to the ANSYS Fluent User's Guide [20], for perforated plate problems (such as the impingement cooling holes in a TCC system) only the inertial term typically needs to be considered. This is because that the viscous term is commonly used for solving problems with laminar flows and it is negligible for flow with high velocities. The benefit of omitting the viscous term is that it reduces the mathematical complexity of the current model presented. The momentum source term, $S$, can be now written as [20]:

$$
S_{i}=-\sum_{j=1}^{3} C_{2_{i j}}\left(\frac{1}{2} \rho V \mathrm{v}_{j}\right)
$$

where $S_{i}$ is the source term for the $i$ th $(x, y$, or $z)$ momentum equation, $C_{2}$ is the inertial resistance factor, $\rho$ is the fluid density in the porous media, $V$ is the magnitude 
of the velocity, and $\mathrm{v}_{j}$ is the velocity components in the $x, y$, and $z$ directions respectively.

Fundamentally, the mass flow through the impingement cooling holes is set by the pressure drop across them. Therefore, for a porous media to be representative of the impingement cooling holes the pressure drop must be the same across both the porous media and the impingement cooling holes, i.e.:

$$
(\Delta P)_{P M}=(\Delta P)_{I H}
$$

By expanding the equation and applying mass flow conservation the inertial resistance factor, $C_{2}$, can be written as:

$$
C_{2}=\frac{K_{L} \times\left((A R)_{1}\right)^{2}}{t}
$$

Where $K_{L}$ is the loss coefficient and is defined as:

$$
K_{L}=\Delta P / p_{d}
$$

$K_{L}$ is a function of the total pressure drop $\Delta P$ and the dynamic head $p_{d}$ across the impingement cooling holes. $(A R)_{1}$ is the area ratio between the porous media used and all the impingement cooling holes, and $t$ is the thickness of the impingement cooling holes. Importantly, in this representation the resistance in the porous media becomes a function of the flow field as well as the geometry of the TCC. It should be possible to define the model in terms of the parameters discussed in Section 1 and the model should also be able to react to variations in system mass flow (for example when cooling demand changes across the engine operating cycle).

The resistance factor $C_{2}$ has to be defined in two directions for 2D problems or three directions for 3D problems. For perforated plate problems the flow through the 
plate is mainly influenced by the perpendicular velocity component (manifold cross flow in Fig. 3); the velocity components in the other two directions (3D problems) are negligible. Thus, much higher values of resistance $C_{2}$ in those two directions should be defined to ensure that the flow through the porous media is perpendicular to the plate; as it would be through actual impingement cooling holes. In practice, this can be achieved by setting the value of $C_{2}$ in the other two directions to be $\sim 100$ times the value in flow direction.

\section{Influence Factors of the Porous Media Pressure Drop}

As shown in equation (3) $C_{2}$ is a function of the loss coefficient $K_{L}$ and geometrical parameters (the area ratio and thickness) of the TCC manifold. As $K_{L}$ is unknown prior to the simulation it needs to be estimated through a sensitivity study of the related parameters and it is only feasible to do this numerically. These parameters include:

(i) the area ratio of the manifold cross-section to the impingement cooling holes $(A R)_{2}$ as this sets the magnitude of the cross-flow ratio,

(ii) the length of the manifold, L,

(iii) the stand-off distance, $h$, between the impingement cooling holes and the turbine casing surface,

(iv) the curvature of the manifold around the engine center-line,

(v) the flow topology generated by the upstream components i.e. the inlet flow angle $\theta$. 
(vi) The temperature difference between the cooling air and the metal surface containing the impingement cooling holes.

To develop a robust method for estimating $K_{L}$ these parameters were examined using a simplified model comprising of a single row of impingement cooling holes. An example model is shown in Fig. 4. Note that for a stand-off distance set to typical engine size it was found that the actual impingement has negligible effect of the IH mass flow and as such a pressure outlet was applied to the exit of the impingement cooling holes, saving computation expense. The typical thickness (or length) to diameter ratio, $t / d$, of the impingement cooling holes was 0.58 and the pitch (spacing) to diameter ratio, $s / d$, was 8.33. The cross-sectional area of manifold was variable to alter the area ratio between the manifold and the impingement cooling holes (with the latter being fixed in the simplified model).

It was found that the area ratio of the manifold cross-section to the impingement cooling holes, $(A R)_{2}$, and the flow topology generated by the upstream components, $\theta$, have the most significant influence on $K_{L}$. Miller [5] also reported the effect of length and area ratio as shown in Fig. 2. However, the lengths of the manifold used in the current research did not have significant effect on the flow distribution of the impingement cooling holes. The lengths chosen were based on the current engine architecture and it was assumed that the lengths investigated were in the same category (short length) as reported by Miller [5] (Fig. 2). Other lengths which are not 
employed in current engine architectures are not of interest to this study and therefore not included in this research.

Close to the junction feeding of the TCC manifold the flow can be complex. The flow impinges on the manifold, large regions of recirculating flow can exist and, in general, there can be large variations in flow angle which affect the feed to the impingement cooling holes, locally alter the discharge coefficient and the resultant mass flow. To overcome this, it is beneficial to have a manifold with a relatively large crosssection. Miller [5] recommends that

$$
\left(\frac{1}{(A R)_{2}}\right)^{2} \leq 0.5
$$

Hence, Miller [5] essentially recommends TCC systems should be designed with $(A R)_{2} \geq 1.4$. However, the physical size of the TCC system is often set at the preliminary design phase such that later changes in the required flow rate and area of the cooling holes often results in the final design being close to or exceeding this criterion. It is therefore important to take the configurations beyond the criterion in determining an expression for estimating $K_{L}$. Hence, several different area ratios were examined in the current investigation; an area ratio of 1 , which is below the critical value of 1.4, and four other values from 2 to 5. To vary the area ratio the cross-sectional area of the manifold was altered whilst maintaining the number and area of the impingement cooling holes.

The flow angle after the junction, $\theta$, is another important factor in determining $K_{L}$; it is well known that the discharge coefficient of a plane hole is strongly influenced by the angle at which the flow approaches. In a typical TCC system, the flow 
far away from the junction becomes fairly uniform whilst the average flow angle after the junction can be as high as $68^{\circ}$ according to previous fully featured investigation of a TCC system (private communication with the industrial partner). This angle was calculated on a cross-sectional plane in the manifold close to the junction. Thus, in the initial simplified model, five different flow angles $\theta$ (for each area ratio) were investigated by altering the flow angle applied to the pressure inlet which are $0^{\circ}, 17^{\circ}$, $34^{\circ}, 51^{\circ}$ and $68^{\circ}$.

The effect of area ratio $(A R)_{2}$ and flow angle, $\theta$, on the mass flow distribution for the simplified cases with impingement cooling holes is shown in Fig. 5. The mass flow through each impingement cooling hole, $m$, is made non-dimensional by the ideal mass flow through each hole if the distribution was uniform, $m_{\text {ideal }}$. With an area ratio $(A R)_{2}$ of 5 the mass flow distribution along the length of the manifold is nominally uniform, as would be expected well beyond the critical area ratio $\left((A R)_{2}\right.$ of 1.4). However, with increasing inlet angle there is a localized reduction of mass flow in the first portion of the manifold. This reaches a maximum deficit of around $5-6 \%$ of the mean at the highest inlet angle. As the area ratio is reduced the general uniformity of the mass flow decreases with a flow deficit seen again in the first portion of the manifold.

Importantly, Fig. 5 (5) shows that the temperature difference between the air and the metal surface containing the impingement cooling holes has only a very small difference on the mass flow distribution. Typically, the temperature difference in an engine is of the order $100 \mathrm{~K}$ and here differences up to $400 \mathrm{~K}$ are examined by setting the wall containing the impingement cooling holes to a raised temperature. Conjugate heat 
transfer and the cooling effect on the metal surface was not modelled and, as such, this represents the largest heat pick-up, and density change, possible for the air. Even at the highest temperature difference changes in the mass flow distribution are much smaller than those caused by changes to the inlet flow angle or bulk geometric parameters. The results shown in Fig. 5 (5), therefore, suitably justify the use of an isothermal approach.

Fig. 6 shows contours of normalized velocity magnitude (over the first 6 out of the 20 holes) for different area ratios with an inlet flow angle of $68^{\circ}$. The velocity magnitude is normalized using the averaged velocity magnitude at the inlet. The contour plots illustrate the 6 impingement cooling holes close to the inlet where the maximum deficit of the mass flow distribution occurs as shown in Fig. 5 . The flow angle boundary condition simulates the impingement effect of flow after the inlet junction. As shown in Fig. 6, with an inclined angle at the inlet there is a separation and recirculation zone on the upper wall. With an approaching angle to the cooling holes, the discharge coefficient will normally decrease due to the reduction in effective area for the cooling flow. For Fig. 6 (1) and (2) the first one or two holes also have a higher cross-hole velocity. As $(A R)_{2}$ decreases (Fig. $6(3),(4)$ and (5)), it negatively influences the blockage inside impingement cooling holes close to the inlet leading to reduced effective area and thus lowers discharge coefficients. Thus, it causes the mass flow deficit in Fig. 5. Towards the end wall of the manifold the system was losing mass flow through impingement cooling holes and thus experienced reduced manifold velocity. With the latter resulting in localized increased values of discharge coefficient and hence increased mass flow through the impingement cooling holes towards the end of the manifold (Fig. 
5). Meanwhile the results also suggested that it followed the trend of flow distribution reported by Miller (Fig. 2) [5].

In terms of developing a suitable expression for a porous media loss coefficient, $K_{L}$, it can be seen in Fig. 5 that, for inlet angles of up to $34^{\circ}$, the variation in mass flow through impingement cooling holes along the manifold has a reasonably linear characteristic with the gradient linked to the area ratio. This would suggest a simple linearly varying loss coefficient would suffice. For example, at low flow angles a normalized profile of the loss coefficient, $K_{L p}$ profile can be treated as linear and written in the form:

$$
K_{L p}=a_{1} L+b_{1}
$$

However, above $34^{\circ}$ the mass flow variation becomes non-linear with this non-linearity also dependent on the area ratio. Hence a more complex specification of the normalized profile of the loss coefficient, $K_{L p}$, is needed which can be written in the form:

$$
K_{L p}=a_{2} L^{b_{2}}
$$

Where $K_{L p}$ is the normalised profile of $K_{L}$,

$$
K_{L}=K_{L A V G} \times K_{L p}
$$

$K_{L A V G}$ is the average value of the loss coefficient of all the impingement cooling holes in the system, $L$ is the non-dimensional length of the manifold, $a_{1}, b_{1}, a_{2}$ and $b_{2}$ are coefficients.

Thus equation ( 3 ) for the inertial resistance factor, $C_{2}$, required by the CFD model now becomes: 


$$
C_{2}=\left(K_{L A V G} \times K_{L p}\right) \times \frac{\left((A R)_{1}\right)^{2}}{t}
$$

Importantly this equation incorporates terms defined or altered by both the system geometry and the resultant flow field. For example, the average loss coefficient, $K_{L A V G}$, sets the bulk pressure drop and hence the bulk mass flow. The profile term, $K_{L p}$, then sets the distribution along the manifold in terms of a non-dimensional length; the profile itself is set by the coefficients $a_{n}$ and $b_{n}$ and overall the resistance coefficient, $C_{2}$, is factored by area ratio $(A R)_{2}$ and the thickness $t$ (or thickness-to-diameter ratio $t / d)$ of the impingement cooling hole.

In order to implement the model two things are now required:

1. A numerical look-up table for the values of the coefficients $a_{1}, b_{1}, a_{2}$ and $b_{2}$. This has been generated from the results of the parametric study of the simple cases with impingement cooling holes. i.e. equations (5) and (6) have been fitted to the data shown in Fig. 5.

2. An initial guess is needed for the average value of the loss coefficient $K_{L A V G}$ to set the bulk mass flow. An initial estimate of $K_{L A V G}$ was chosen to be 2 for all cases with porous media. This can then be iterated numerically until a target TCC mass flow (obtained here from the corresponding predictions with impingement cooling holes) is achieved.

\section{PROOF OF CONCEPT}

In this section verification of the porous media methodology is presented by applying it to several different configurations broadly representative, non- 
dimensionally, of typical engine geometries. By keeping the model as simple as possible results from these proof-of-concept predictions can be directly compared to cases which still include the impingement cooling holes. Hence the validity of the porous media representation can be demonstrated over a range of geometrical and aerodynamic parameters. These includes varying the manifold cross-section to impingement hole area ratio $(A R)_{2}$, the manifold length, and the hole thickness-todiameter ratio $t / d$. The change was made to one parameter at a time with the rest of parameters kept the same. These were all varied in line with typical values seen in current TCC systems. Additionally, better assess the effect of inlet flow angle a generic junction (or feed pipe) was added to generate a more realistic distribution of flow angles instead of imposing a single artificial inlet angle. For simplicity, from herein, $\mathrm{IH}$ will be used to refer to cases with impingement cooling hole features whilst PM will be used to refer to cases where these are replaced by porous media.

\section{Computational Domains and Boundary Conditions}

The computational domains are illustrated in Fig. 7 and 8. Each incorporate a single row of 20 impingement cooling holes (or the porous media representation) with a thickness-to-diameter ratio, $t / d$, of 0.58 and a pitch-to-diameter ratio $s / d$ of 6.67 and 8.33 in the $x$ and $y$ directions with periodic side-walls in the $x$ direction. Four different manifold cross-sections to $\mathrm{IH}$ area ratios were modelled, $(A R)_{2}$ of 1 to 4 , and these were again achieved by altering the manifold cross-sectional area. A T-shaped inlet was modelled with using only half of the geometry and a symmetry boundary condition (Fig. 
7). This essentially represents the same length of the manifold on each side of the Tshaped inlet. This was also modelled without the symmetry condition enabling different lengths of manifold to be incorporated either side of the inlet (Fig. 8). A short length was included upstream of the junction with a length twice that of the hydraulic diameter. This was done to ensure the fixed inlet boundary condition did not constrain the flow in the junction. Several inlet lengths were examined, and it was found that two hydraulic diameters were sufficient. Finally, another model was also generated which included circumferential curvature close to that expected in the TCC system of a large civil turbofan.

\section{Results and Discussions}

Sensitivity to Area Ratio, $(A R)_{2}$

Fig. 9 shows the normalized mass flow distribution for the cases with the same length of manifold on each side of the T-shaped junction for four different area ratios $(A R)_{2}$. The mass flow through each impingement cooling hole or equivalent porous media, $m$, is made non-dimensional by the ideal mass flow through each hole (or equivalent) if the distribution was uniform, $m_{\text {ideal }}$.

It was shown in Fig. 5 that the heating effect on the air caused by the manifold has only a negligibly small effect on the mass flow distribution when compared to changes in the area ratio or inlet flow angle. This is also confirmed here in Fig. 9 (4) which shows little difference in the overall mass flow distribution for temperature 
differences of up to $400 \mathrm{~K}$. Again, this justifies the use of an isothermal model to reduce model complexity and calculation time.

With an area ratio of 4 the results from the PM case show good agreement to the $\mathrm{IH}$ case with the differences within $5 \%$ of the average mass flow rate. However, as the area ratio is reduced the porous media methodology does not correctly predict the region under inlet feed pipe. The resistance profiles applied are based on data collected from models without a junction and it is clear that this simplification becomes somewhat invalid at low area ratios. With reference to the mass flow distributions plotted in Fig. 5 this approach yields the highest resistance at the beginning of the porous media. However, with a junction included in the model the impingement cooling hole(s) under the junction have a total feed (Fig. 10) which results in the higher mass flow seen in the first impingement cooling hole in Fig. 9. Additionally, as the PM predicts a lower mass flow over the first $5-10 \%$ this results in a slightly higher flow in the rest of the porous media to compensate and maintain the total mass flow. Yet, the PM model predicted the flow feature very well inside the manifold for all four different $(A R)_{2}$. Inclusion of some IH or some other special treatment under the junction is required to accurately capture the mass flow distribution. Nevertheless, the current model still does a good job away from the junction.

To investigate the flow features inside the manifold, Fig. 10 shows contours of normalized velocity magnitude for different area ratios. Note that the plot shows only the first 7 out $20 \mathrm{IH}$ and that the CFD only simulated half of the T-shaped inlet (using a symmetry boundary condition). Each subfigure shows the comparison between the IH 
and PM cases with the same area ratio, $(A R)_{2}$. Note that to alter the area ratio $(A R)_{2}$, by altering the manifold area, it is somewhat difficult to keep all the other parameters consistent. For example, the area ratio between the junction and the manifold was kept the same as was the $\mathrm{IH}$ area and spacing. The position of the first $\mathrm{IH}$ was maintained at the same non-dimensional location with respect to inlet which unfortunately changes the initial IH spacing. However, regarding a direct comparison with the performance of the PM model this is not a major issue. In general, the PM method correctly predicts the flow in the manifold with $(\mathrm{AR})_{2}$ from 1 to 4 . The PM method does not predict the mass flow distribution well close to the inlet (Fig. 9). Here the flow is close to a total feed which has (as yet) not been incorporated into the PM model. However, it should be possible to construct a PM treatment to account for this or perhaps keep a small number of $\mathrm{IH}$ in this region is the final model.

\section{Sensitivity to $t / d$ Ratio}

In practical TCC systems it is often necessary to have regions of holes with different diameters to control local cooling flows. As mentioned previously the thickness of the manifold casing is often defined early in the design process which then fixes the length of the impingement cooling holes. If a change in flow rate is then desired, it is achieved by varying the hole diameter. In some other cases, the manifold configurations are designed different with different casing thickness for different engine configurations while cooling hole diameters may be fixed by tooling specification. Hence these constraints lead to variations in the thickness-to-diameter ratio, $t / d$, and it is important 
that a robust PM methodology should have the capability to model this. To investigate the effect of varying $t / d$ ratio several IH models were generated varying both the hole diameter and the manifold thickness. With the initial thickness of the holes fixed the diameter was varied to achieve $t / d$ ratios of $0.23,0.35$ and 0.70 . Similarly, with the hole diameter fixed the thickness was varied to achieve $t / d$ ratios of $0.42,0.83$ and 1.25 . See Table 1. Note that the pitch, $s$, remained constant. Two different area ratios $(A R)_{2}$, were modelled: $(A R)_{2}$ of 2 which is above the critical value (1.41) and $(A R)_{2}$ of 1 which is below that value.

The effect of $t / d$ ratio on the mass flow distribution of the impingement cooling holes with a T-shaped inlet is shown in Fig. 11. These cases were also predicted using a symmetry boundary condition at the center of the T-shaped inlet junction. The mass flow distribution is comparatively flat except when the $t / d$ ratio is lower than 0.4 . However, even with $t / d$ ratio higher than 0.4 the maximum deficit of mass flow rate is around $17 \%$ difference from the average value. As shown in Fig. 12 (normalized velocity magnitude contours over the first 7 out of $20 \mathrm{IH}$ ) with lower $t / d$ ratios $(0.23$ and 0.35$)$, the discharge coefficients of the cooling holes (thus the mass flow rate) are much more sensitive to the local flow feed. In the region close to the inlet, the total feed and low $t / d$ ratio (larger diameter) together will result in higher mass flow rates. With fed by the cross flow in high velocity just after the junction, the discharge coefficient is low due to the blockage in the cooling holes and reduction in the effective area of the vena contracta. As the manifold flow velocity decreases from losing flow through cooling holes, both the discharge coefficient and mass flow rates increase. The cases with $(A R)_{2}$ 
of 1 have similar results as shown in Fig. 12 but the $t / d$ ratio effect is worse. This phenomenon observed after the junction is the same as seen in the IH cases without the junction.

Based on previously experience (from the industrial partner) it is unlikely that a $t / d$ ratio will be lower than 0.35 in the current engine architectures. Therefore, for the porous media methodology it is important to verify its validity at this lower limit of $t / d$ $=0.35$. Hence, Fig. 13 shows a comparison between the $\mathrm{IH}$ and $\mathrm{PM}$ case with a $t / d$ ratio of 0.35 at two different area ratios $(A R)_{2}$. Although the porous media methodology does not predict the exact flow behavior close to the junction region there is still reasonable agreement in the trend of the mass flow distribution as for the $\mathrm{IH}$ cases for $(A R)_{2}$ of 2 (Fig. 13). However, the porous media methodology meets its limit with $(A R)_{2}$ of 1 together with a low $t / d$ ratio of 0.35 .

\section{Sensitivity to T-Shaped Inlet with Different Length of Manifold on Each Side}

Previous sections have discussed the sensitivity of the porous media methodology to several parameters. All those parameters have been investigated on computational domains with the same length of manifold on both sides of the T junction. In some TCC systems the T-shaped inlet may feed manifolds of differing lengths and having different arrangement of cooling holes and thus different mass flow (Fig. 8). Additionally, TCC systems will have curvature which is also thus far been omitted. This section also aims to address how the porous media approach copes with this by examining the models shown in Fig. 8; both with impingement cooling holes and 
porous media. Predictions were made for cases with different area ratios, $(A R)_{2}$ of 1 and 2 and for various levels of curvature. In addition to the no curvature cases two levels of curvature were examined which were broadly representative of those seen in the HP and LP turbines in a large civil turbofan. The level curvature is defined, nondimensionally [23], as the ratio of the hydraulic diameter, $D$, of the manifold passage to its radius of curvature, $R$, about the engine center line:

$$
\delta=\frac{D}{2 R}
$$

Where $D$ is the hydraulic diameter of manifold passage and $R$ is the radius of the manifold about the engine center-line. For a typical HP turbine the higher level of curvature gives rise to $\delta \sim 0.02$ whilst for the LP turbine the increased radius reduces $\delta$ to 0.01 .

There are 77 impingement cooling holes in the computational domain (Fig. 8). The porous zone was divided into two parts from the middle of the junction and the PM method was applied to each part separately to match the mass flow split after the junction.

Fig. 14 (1) compares the predicted mass flow distributions for the IH cases with/without curvature and, as seen in the figure, the curvature does not have any significant effect on the mass flow distribution through the impingement cooling holes Subsequently, Fig. 14 (2) compares the mass flow distribution for both IH and PM cases for a fixed curvature $(\delta=0.01)$ for two different area ratios, $(A R)_{2}$. The plot highlights a significant variation in the mass flow beneath the inlet pipe which is magnified by the 
reduction in $(A R)_{2}$. The mismatch along the manifold was due to the combination of the poor prediction of the junction region and mass flow conservation law.

Contours of normalized velocity magnitude for the cases shown in Fig. 14 are presented in Figs. 15 and 16 (note the whole domain is not shown, just the area local to the T junction - refer to Fig. 8). The velocity contours are not symmetric about the T junction which is due to the different flow splits defined by different length of manifold. A longer manifold has a more $\mathrm{IH}$, more cooling flow and hence a smaller $(A R)_{2}$. The higher velocities shown in Figs. 15 and 16 are caused by the combination of more mass flow and smaller $(A R)_{2}$. Fig. 15 illustrates that the levels of curvature investigated did not have a significant effect on the flow for both $(A R)_{2}$. Consequently, for brevity Fig. 16 shows the PM cases for a single $(A R)_{2}=2$. For both levels of curvature, the PM method adequately predicts the bulk flow in the manifold. However, as shown in Fig. 14 and discussed above, it does not correctly capture the mass the mass flow distribution through the IH directly under the inlet. The impingement from the inlet flow and total feed to the porous zone beneath increases the discharge coefficient and thus the mass flow rate. This isn't captured by the PM which applies a (too) high resistance in the porous zone. It is recommended that the impingement cooling hole features should be kept under the inlet pipe and porous media then could be employed in the regions after the junction. 


\section{CONCLUSIONS}

A porous media methodology has been developed for the CFD modelling of turbine case cooling (TCC) systems used in aero style gas turbines. In this approach, the impingement cooling holes were replaced by porous media zones in the computational domain. Importantly this leads to a significant reduction in mesh size and computational time making the approach suitable for use as a design tool. The porous media methodology employed numerically defined correlations linked to the system geometry and the local flow field to specify a porous media loss coefficient. Included as a user defined function this allows the loss coefficient to vary as a function of the predicted flow and hence produce a spatial variation of mass flow which matches that of the impingement cooling holes. The methodology was shown to be valid by applying it to various simplified geometrical configurations representative of current TCC systems and comparing the results to configurations including impingement cooling holes. The overall flow field was good agreement with the impingement cooling hole configurations whilst achieving a significantly reduction the mesh count and reducing the computational time to a practical level.

\section{ACKNOWLEDGMENT}

This research was undertaken at Loughborough University within the Rolls-Royce University Technology Centre (UTC) in Combustion System Aero Thermal Processes. It was funded by the Aerospace Technology Institute and Rolls-Royce plc. 


\section{NOMENCLATURE}

$(A R)_{1} \quad$ area ratio between the porous media used and the impingement cooling holes

$(A R)_{2}$ area ratio between the cross-section of the TCC manifold and the impingement cooling holes (on one side of the junction)

$a_{n}, b_{n} \quad$ coefficients of the loss coefficient profile, $n$ is the number notation

CFD Computational Fluid Dynamics

$C_{2} \quad$ the inertial resistance factor in the porous media

$d \quad$ diameter of impingement cooling holes

$D \quad$ diameter or hydraulic diameter of the manifold passage

$h \quad$ standoff height; distance between $\mathrm{IH}$ and turbine casing

IH impingement cooling holes

$i, j \quad$ co-ordinates of $(x, y$, or $z)$ directions

$K_{L} \quad$ loss coefficient

$K_{L A V G} \quad$ average value of the loss coefficient

$K_{L p} \quad$ loss coefficient profile

$L \quad$ non-dimensional length of the TCC manifold

$m \quad$ local mass flow (e.g. through an impingement cooling hole or equivalent porous media) 
mideall Ideal mass flow through each impingement cooling hole (or equivalent porous media) for a uniform distribution

PM porous media

$p_{d} \quad$ dynamic pressure

$\Delta P \quad$ total pressure drop

$R \quad$ radius of the manifold

$S \quad$ momentum source term

$s \quad$ spacing between impingement cooling holes in the same array

$S_{i} \quad$ momentum source term for the $i$ th $(x, y$, or $z)$ momentum equation

$t \quad$ sheet thickness of TCC manifold

TCC Turbine Case Cooling

$V \quad$ velocity magnitude

$v \quad$ fluid velocity

$\mathrm{V}_{\text {inlet }} \quad$ velocity magnitude at the inlet of the computational domain

$\delta \quad$ non-dimensional curvature

$\theta \quad$ flow angle in the manifold after the junction

$\rho \quad$ fluid density in the porous media 


\section{REFERENCES}

[1] Lattime S. B. and Steinetz B. M., 2004, "High-pressure turbine engine clearance control systems: Current practices and future directions", AIAA Journal of Propulsion and Power, 20(2), pp. 302-311, DOI: 10.2514/1.9255.

[2] Lattime S. B., Steinetz B. M. and Robbie M. G., 2005, "Test rig for evaluating active turbine blade tip clearance control concepts", AIAA Journal of Propulsion and Power, 21(3), pp. 552-563, DOI: 10.2514/1.7341

[3] Melcher K. J. and Kypuros J. A., 2003, "Towards a fast-response active turbine tip clearance control", NASA/TM-2003-212627/REV1.

[4] Andreini, A., Soghe, R. D., Facchini, B., Maiuolo, F., Tarchi, L. and Coutandin D., 2013, “Experimental and Numerical Analysis of Multiple Impingement Jet Arrays for an Active Clearance Control System", Journal of Turbomachinery, 135(3), pp. 031016-1 - 031016-9, DOI: 10.1115/1.4007481.

[5] Miller, D. S., 1990, Internal Fluid Systems, $2^{\text {nd }}$ ed., pp. 92-94, ISBN: 978-0956200204.

[6] Laxmi K. M., Kumar V. R. and Rao Y. V. H., 2013, "Modelling and simulation of gas flow velocity in catalytic converter with porous", International Journal of Engineering Research and Application, 3(3), pp. 518-522, ISSN: 2248-9622.

[7] Pitsh S., Holmberg S. and Angster J., 2010, "Ventilation system design for a church pipe organ using numerical simulation and on-site measurement", Building and Environment, 45(12), pp. 2629-2643, DOI: 10.1016/j.buildenv.2010.05.022.

[8] Alshare A. A., Simon T. W. and Strykowski P. J., 2010, "Simulations of flow and heat transfer in a serpentine heat exchanger having dispersed resistance with porous- 
continuum and continuum models", International Journal of Heat and Mass Transfer, 53(5/6), pp. 1088-1099, DOI: 10.1016/j.ijheatmasstransfer.2009.11.002.

[9] Missirlis D., Yakinthos K., Storm P. and Goulas A., 2007, "Modelling pressure drop of inclined flow through a heat exchanger for aero-engine applications", International Journal of Heat and Fluid Flow, 28(3), pp. 512-515, DOI: 10.1016/j.ijheatfluidflow.2006.06.005.

[10] Patursson $\varnothing$. ., Swift M. R., and Tsukrov I., Simonsen K., Baldwin K., Fredriksson D. W. and Celikkol B., 2010, "Development of a porous media model with application to flow through and around a net panel", Ocean Engineering, 37(2-3), pp. 314-324, DOI: 10.1016/j.oceaneng.2009.10.001.

[11] Vasilic K., Meng B., Kühne H. C. and Roussel N., 2011, "Flow of fresh concrete through steel bars: A porous medium analogy", Cement and Concrete Research, 41(5), pp. 496-503, DOI: 10.1016/j.cemconres.2011.01.013.

[12] Ford, C. L., Carrotte J. F. and Walker A. D., 2013, "The application of porous media to simulate the upstream effects of gas turbine injector swirl vanes", Computers \& Fluids, 77, pp. 143-151, DOI: 10.1016/j.compfluid.2013.03.001.

[13] Pruthviraj U., Yaragal S. C. and Nagaraj M. K., 2013, "Numerical prediction of air flow through perforated plates on flat surface", International Journal of Innovative Research in Science, Engineering and Technology, 2(7), pp. 2863-2869, ISSN: 23198753. 
[14] Hwang J. J. and Cheng C. S., 2001, "Impingement cooling in triangular ducts using an array of side-entry wall jets", International Journal of Heat and Mass Transfer, 44(5), pp. 1053-1063, DOI: 10.1016/S0017-9310(00)00141-1.

[15] Rowbury D. A., Oldfield M. L. G. and Lock G. D., 2001, “A method for correlating the influence of external crossflow on the discharge coefficients of film cooling holes", ASME Journal of Turbomachinery, 123(2), pp. 258-265, DOI: 10.1115/1.1354137

[16] Chi Z., Kan R., Ren J. and Jiang H., 2013, “Experimental and numerical study of the anti-crossflows impingement cooling structure", International Journal of Heat and Mass Transfer, 64, pp. 567-580, DOI: 10.1016/j.ijheatmasstransfer.2013.04.052.

[17] Bailey J. C., Intile J., Fric T. F., Tolpadi A. K., Nirmalan N. V. and Bunker R. S., 2003, "Experimental and numerical study of heat transfer in a gas turbine combustor liner", ASME Journal of Engineering for Gas Turbines and Power, 125(4), pp. 9941002, DOI: $10.1115 / 1.1615256$.

[18] Spring S., Lauffer D., Weigand B. and Hase M., 2010, "Experimental and numerical investigation of impingement cooling in a combustor liner heat shield", ASME Journal of Turbomachinery, 132(1), pp. 011003-1-011003-10, DOI: 10.1115/1.3103924.

[19] Da Soghe. R. and Andreini A., 2013, "Numerical characterization of pressure drop across the manifold of turbine casing cooling system", ASME Journal of Turbomachinery, 135(3), pp. 031017-1-031017-9, DOI: 10.1115/1.4007506.

[20] ANSYS Fluent, 2013, ANSYS Fluent User's Guide r15, “Chapter 6: Cell zone and boundary conditions", pp. 223-247. 
[21] Hoque M.M., Alam M. M., Ferdows M. and Beg O.A., 2013, "Numerical simulation of Dean number and curvature effects on magneto-biofluid flow through a curved conduit", Proc IMechE Part H: Journal of Engineering in Medicine, 227(11), pp. 1155-1170, DOI: 10.1177/0954411913493844.

Table 1 Geometrical Variations for $\mathrm{t} / \mathrm{d}$ ratio

\begin{tabular}{|c|c|c|c|c|}
\hline $\mathbf{t} / \mathbf{d}$ & $\mathbf{0 . 2 3}$ & 0.35 & $\mathbf{0 . 5 8}$ & $\mathbf{0 . 7}$ \\
\hline $\mathbf{t}(\mathbf{m m})$ & \multicolumn{4}{|c|}{0.7} \\
\hline $\mathbf{d}(\mathbf{m m})$ & 3.0 & 2.0 & 1.2 & 1.0 \\
\hline $\mathbf{s} / \mathbf{d}$ & 3.3 & 5.0 & 8.3 & 10 \\
\hline
\end{tabular}

(1) Constant thickness, $t=0.7 \mathrm{~mm}$

\begin{tabular}{|c|c|c|c|c|}
\hline t/d & $\mathbf{0 . 4 2}$ & $\mathbf{0 . 5 8}$ & $\mathbf{0 . 8 3}$ & $\mathbf{1 . 2 5}$ \\
\hline $\mathbf{t}(\mathbf{m m})$ & 0.5 & 0.7 & 1.0 & 1.5 \\
\hline $\mathbf{d}(\mathrm{mm})$ & \multicolumn{5}{|c|}{1.2} \\
\hline s/d & \multicolumn{5}{|c|}{8.3} \\
\hline
\end{tabular}

(2) Constant IH diameter, $\mathrm{d}=1.2 \mathrm{~mm}$ 
Fig. 1 Typical TCC System

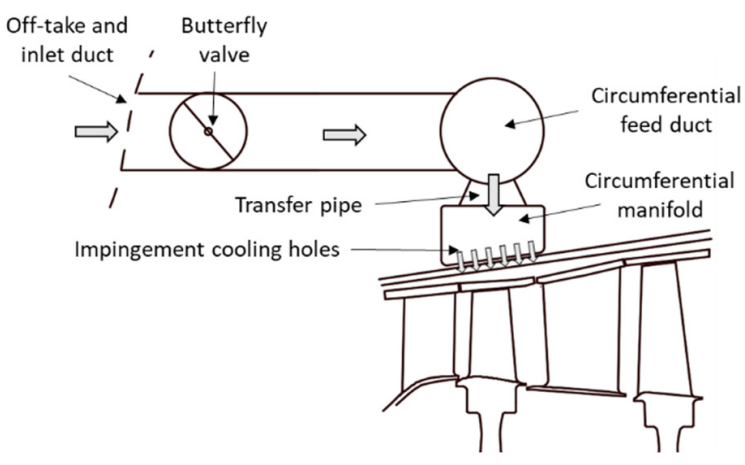

(1) Side view

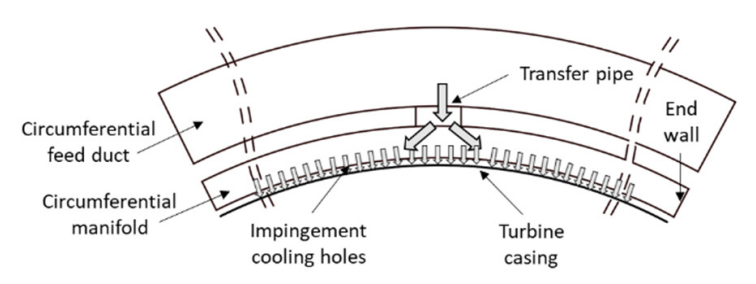

(2) End view

Fig. 2 Manifold flow distribution [5]

\begin{tabular}{|c|c|c|c|}
\hline Manifold Iength & Short & Medium & Long \\
\hline $\begin{array}{l}\text { Low branch } \\
\text { loss ration } \\
(<0.5)\end{array}$ & $\Rightarrow+4+1$ & प+4+4+14+4+4 & $\Rightarrow+14+4+49444$ \\
\hline $\begin{array}{l}\text { Medium branch } \\
\text { lesss ratio" } \\
(<0.7)\end{array}$ & $\Longrightarrow$ & 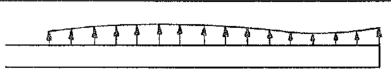 & 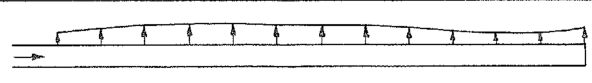 \\
\hline $\begin{array}{l}\text { High tranch } \\
\text { loss ratitio" } \\
(>1 .(1)\end{array}$ & $\Rightarrow$ का & THAMH... & 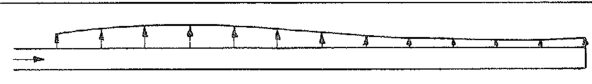 \\
\hline
\end{tabular}


Fig. 3 Porous media representation of impingement cooling holes

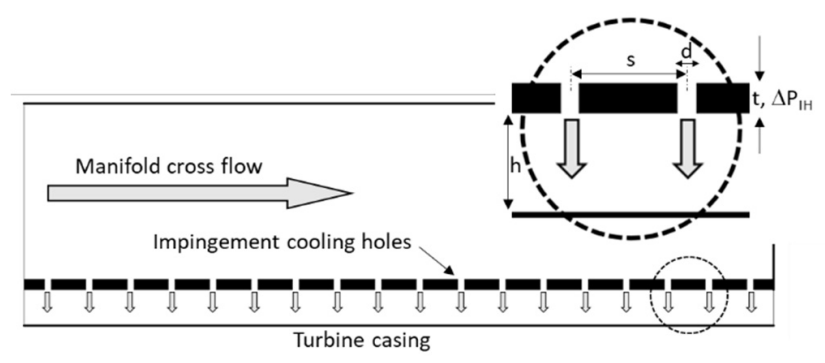

(1) Perforated plate (typical of impingement cooling holes)

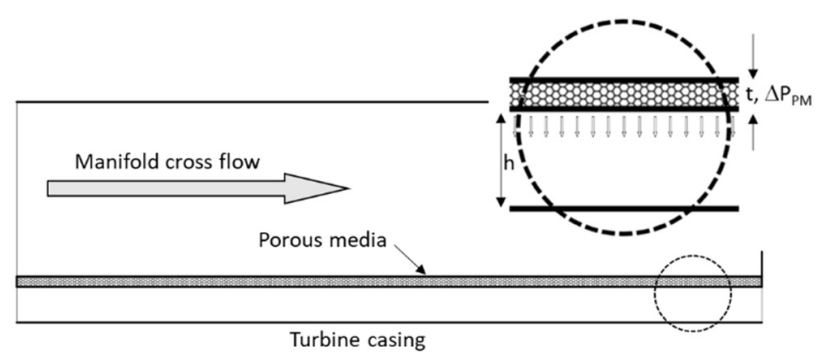

(2) Porous media

Fig. 4 An example of the computational domain used for the sensitivity study

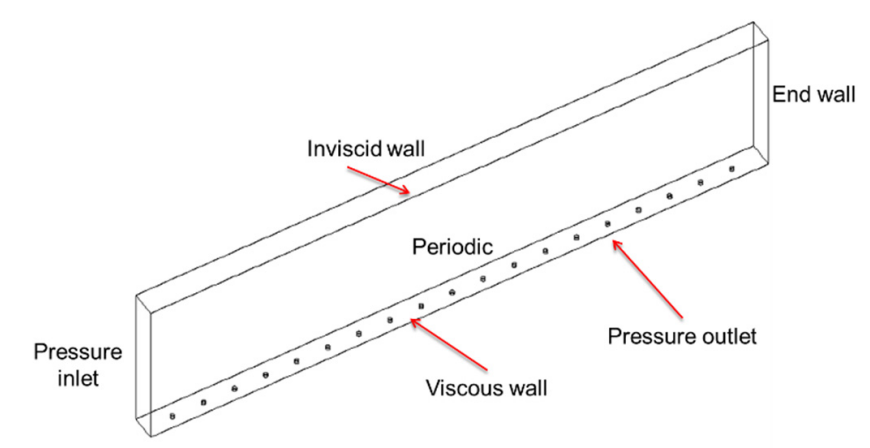


Fig. 5 Effect of flow angle and area ratio on mass flow distribution

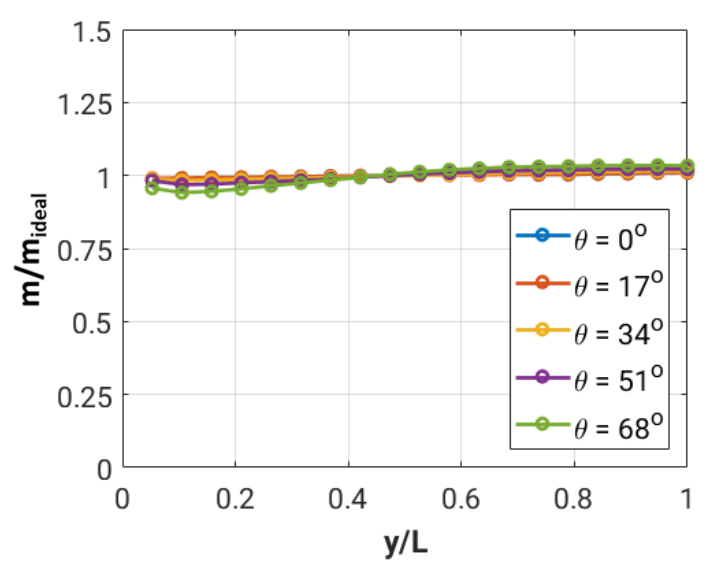

(1) $(A R)_{2}=5$

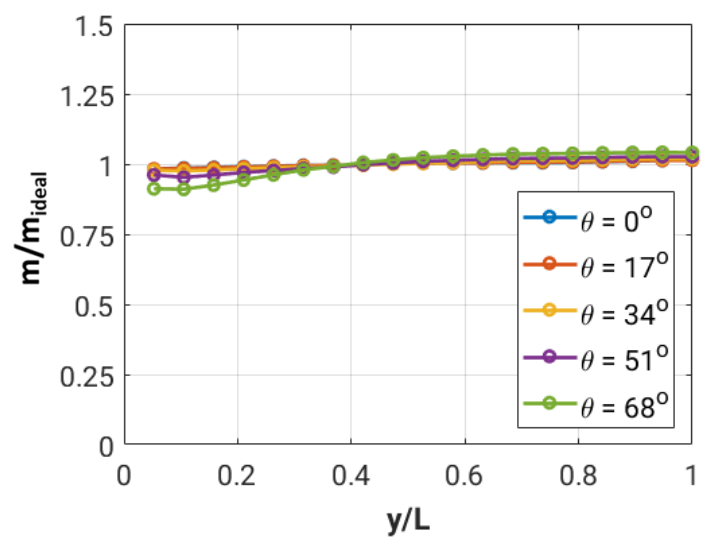

(2) $(A R)_{2}=4$

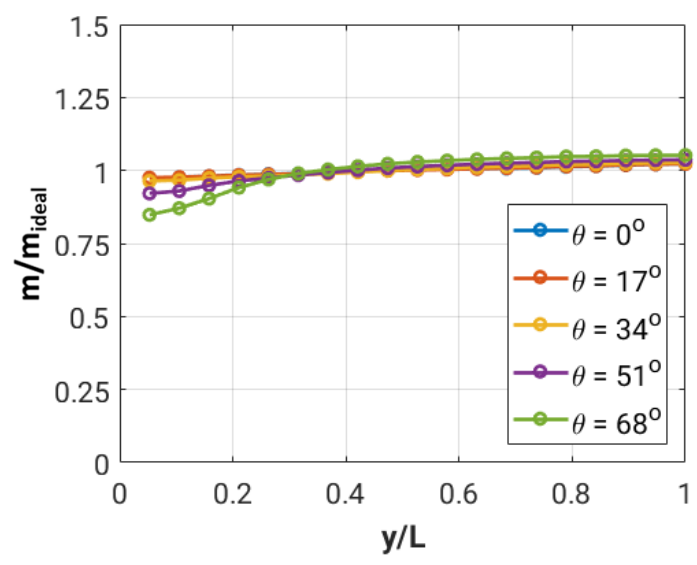

(3) $(A R)_{2}=3$ 


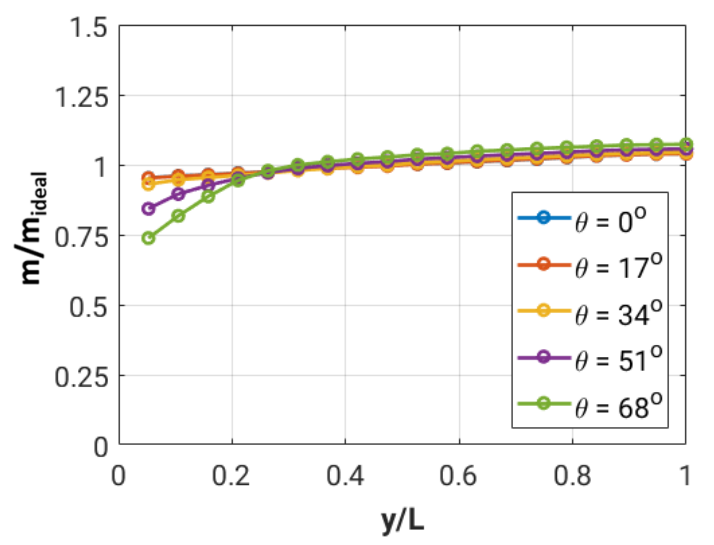

(4) $(A R)_{2}=2$

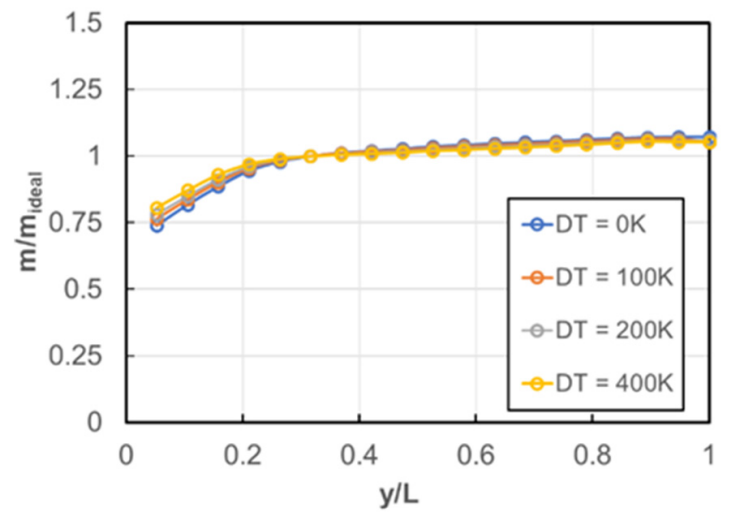

(5) $(A R)_{2}=2, \Delta \mathrm{T}=0-400 \mathrm{~K}$

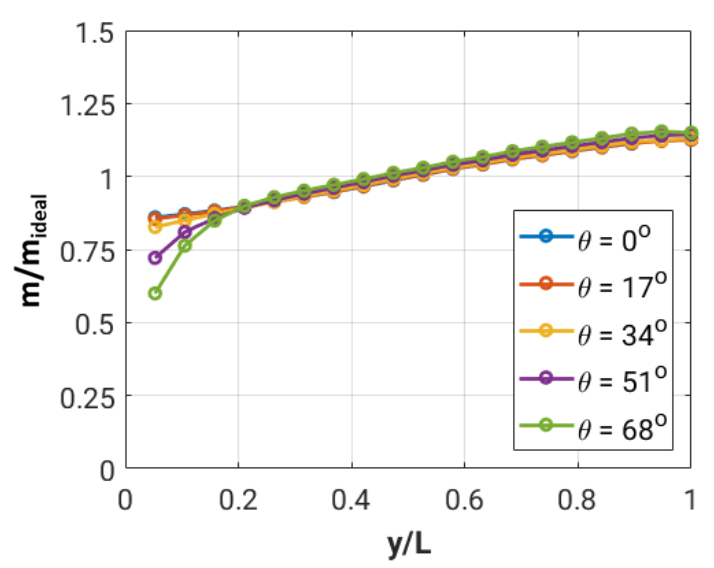

(6) $(A R)_{2}=1$ 
Fig. 6 Normalized velocity magnitude contour plots with $\theta=6^{\circ}$ (showing 6 out of 20

IH)

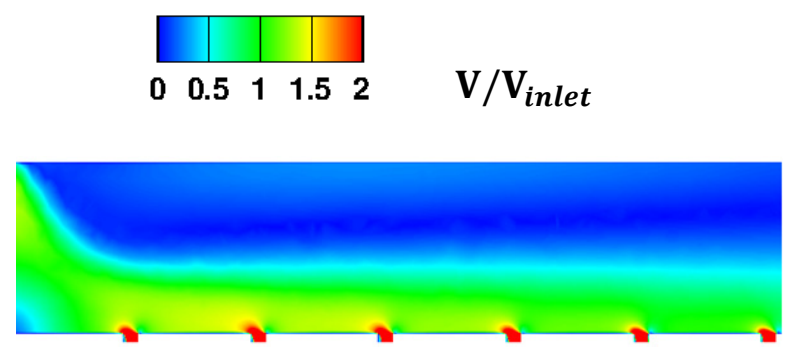

(1) $(A R)_{2}=5$

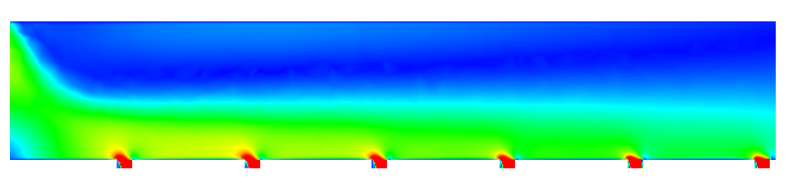

(2) $(A R)_{2}=4$

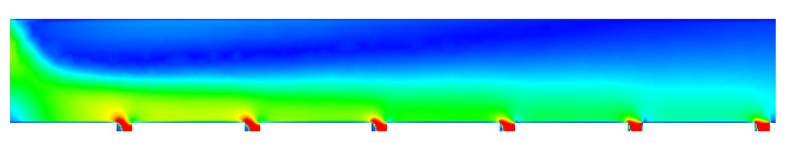

(3) $(A R)_{2}=3$

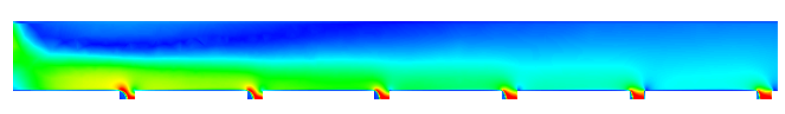

(4) $(A R)_{2}=2$

(5) $(A R)_{2}=1$ 
Fig. 7 Computational domains with T-Shaped inlet $(t / d=0.58, s / d=8.33)$

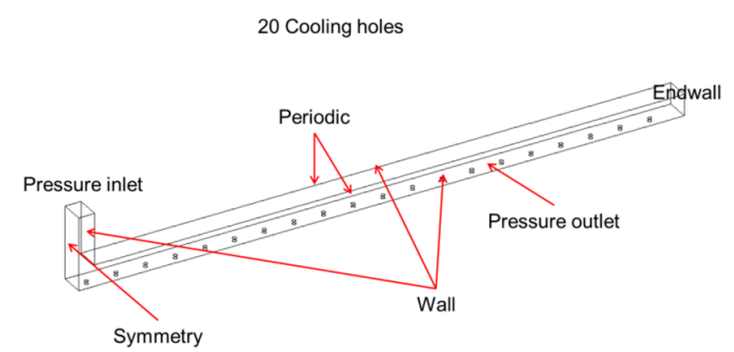

(1) IH case

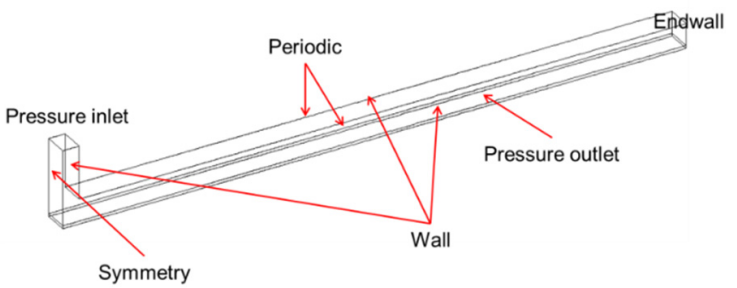

(2) PM case

Fig. 8 Computational domains with T-Shaped inlet $(t / d=0.58, s / d=8.33)$

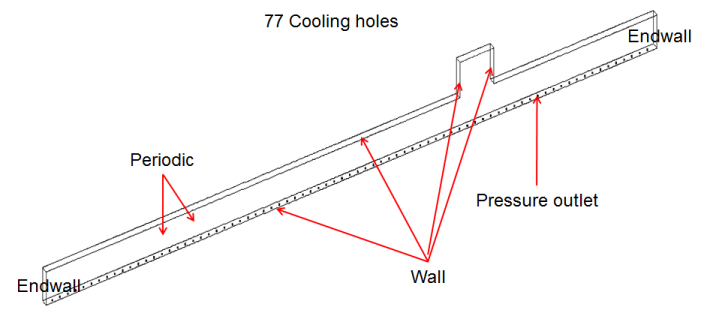

(1) Without curvature

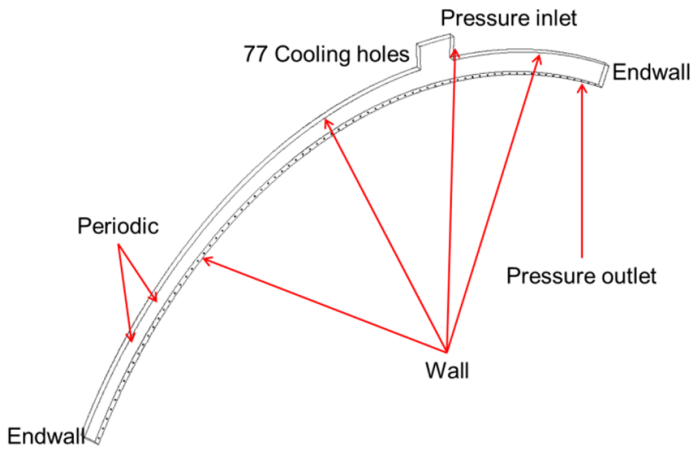

(2) With curvature 
Fig. 9 Mass flow distributions for cases with T-shaped inlet

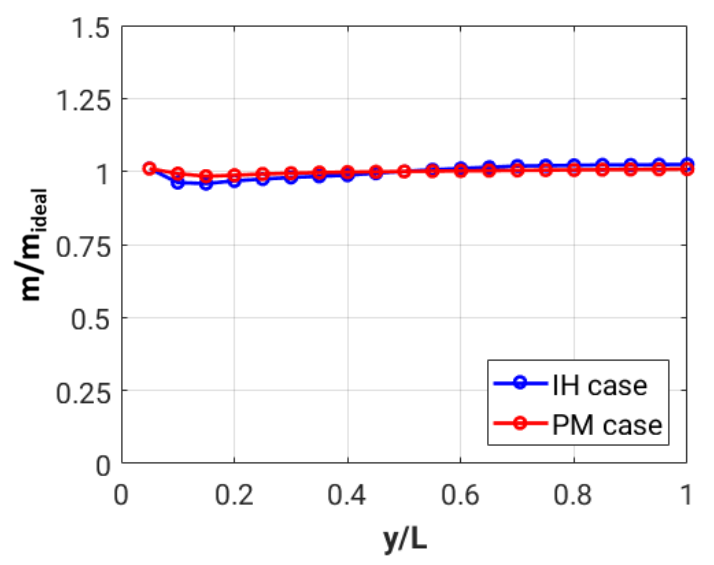

(1) $(A R)_{2}=4$

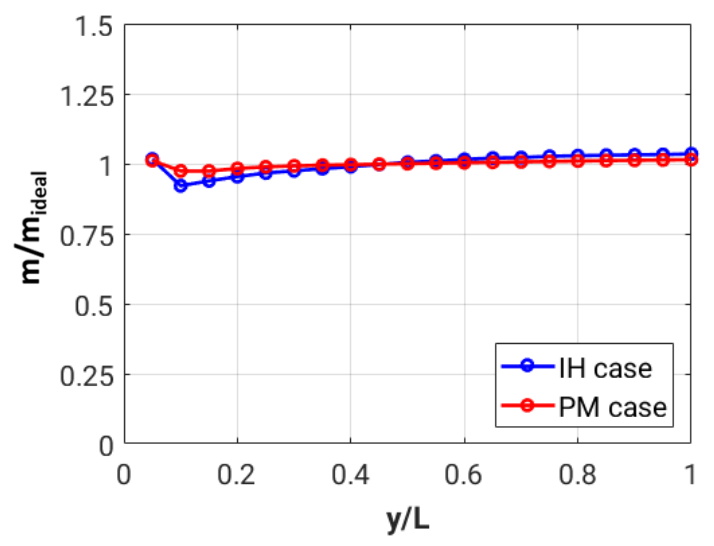

(2) $(A R)_{2}=3$

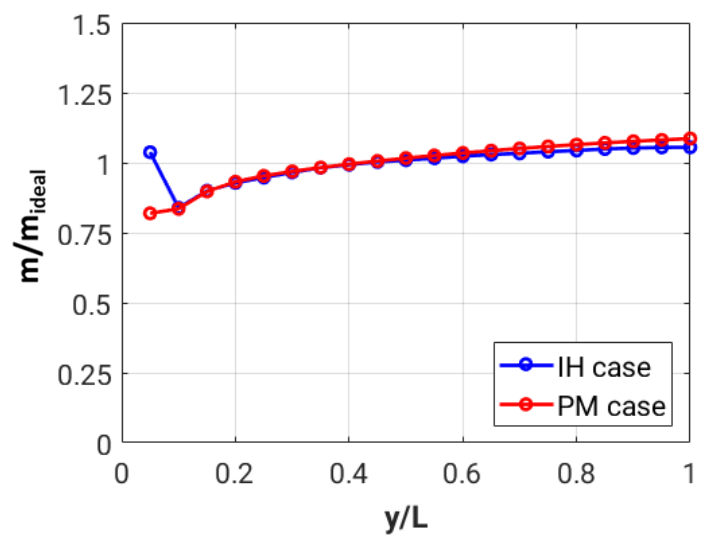

(3) $(A R)_{2}=2$ 


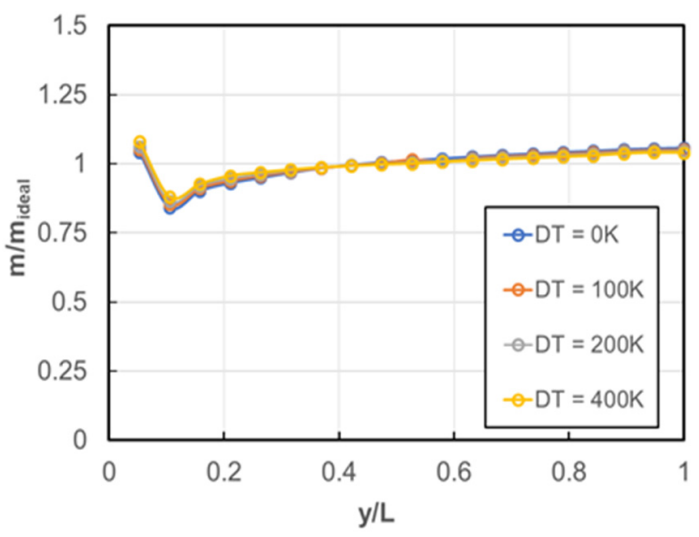

(4) $(A R)_{2}=2, \Delta \mathrm{T}=0-400 \mathrm{~K}$

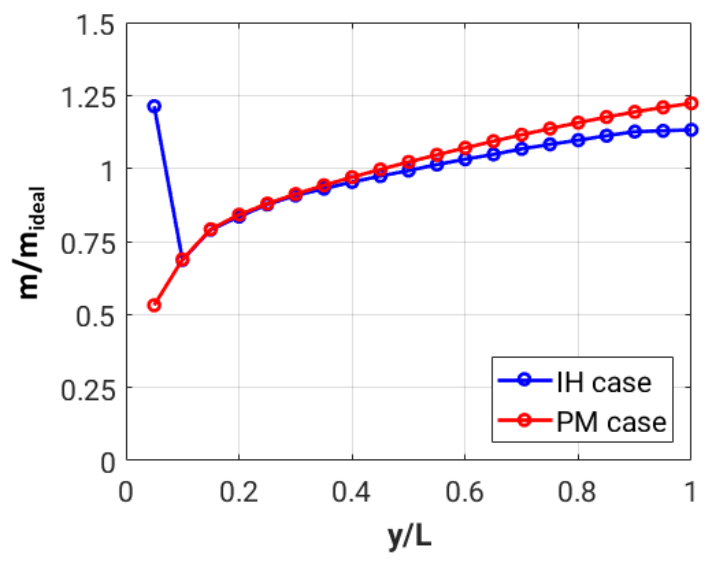

(5) $(A R)_{2}=1$ 
Fig. 10 Normalized velocity magnitude contour pots (left: IH case; right: PM case, showing first 7 out of $20 \mathrm{IH}$ )
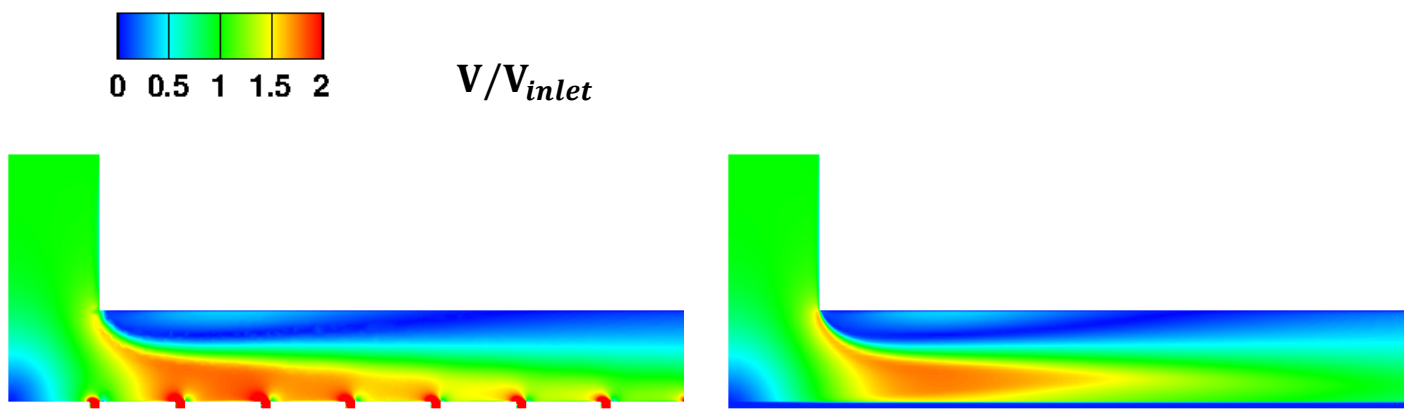

(1) $(A R)_{2}=4$
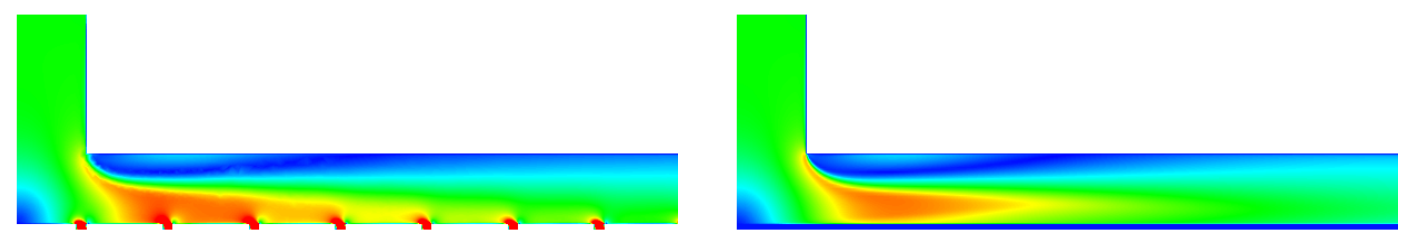

(2) $(A R)_{2}=3$
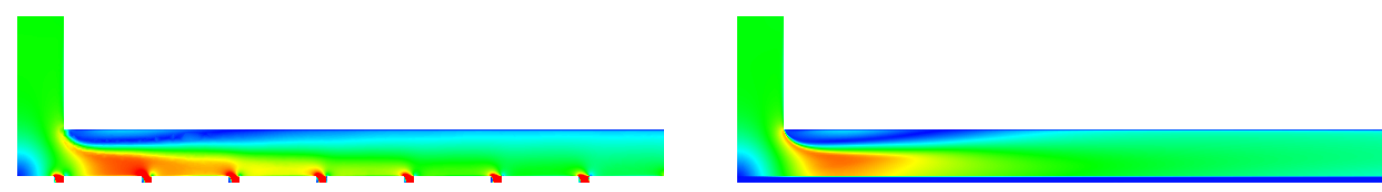

(3) $(A R)_{2}=2$
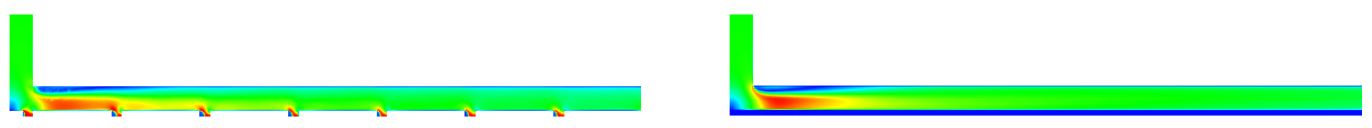

(4) $(A R)_{2}=1$ 
Fig. 11 Effect of $t / d$ on normalised mass flow distribution

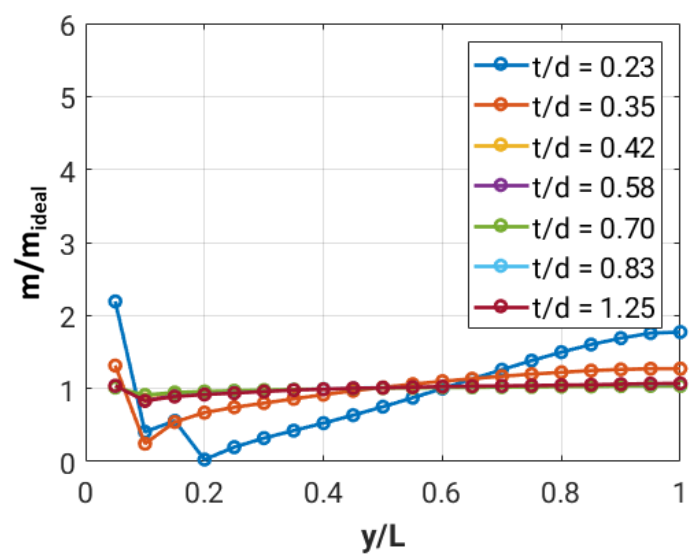

(1) $(A R)_{2}=2$

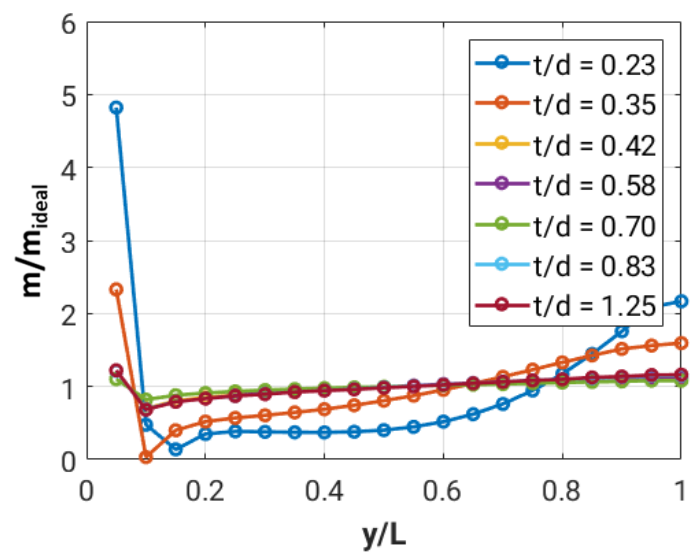

(2) $(A R)_{2}=1$ 
Fig. 12 Normalized velocity magnitude contour plots with $(A R)_{2}=2$ (showing 7 out of $20 \mathrm{IH})$
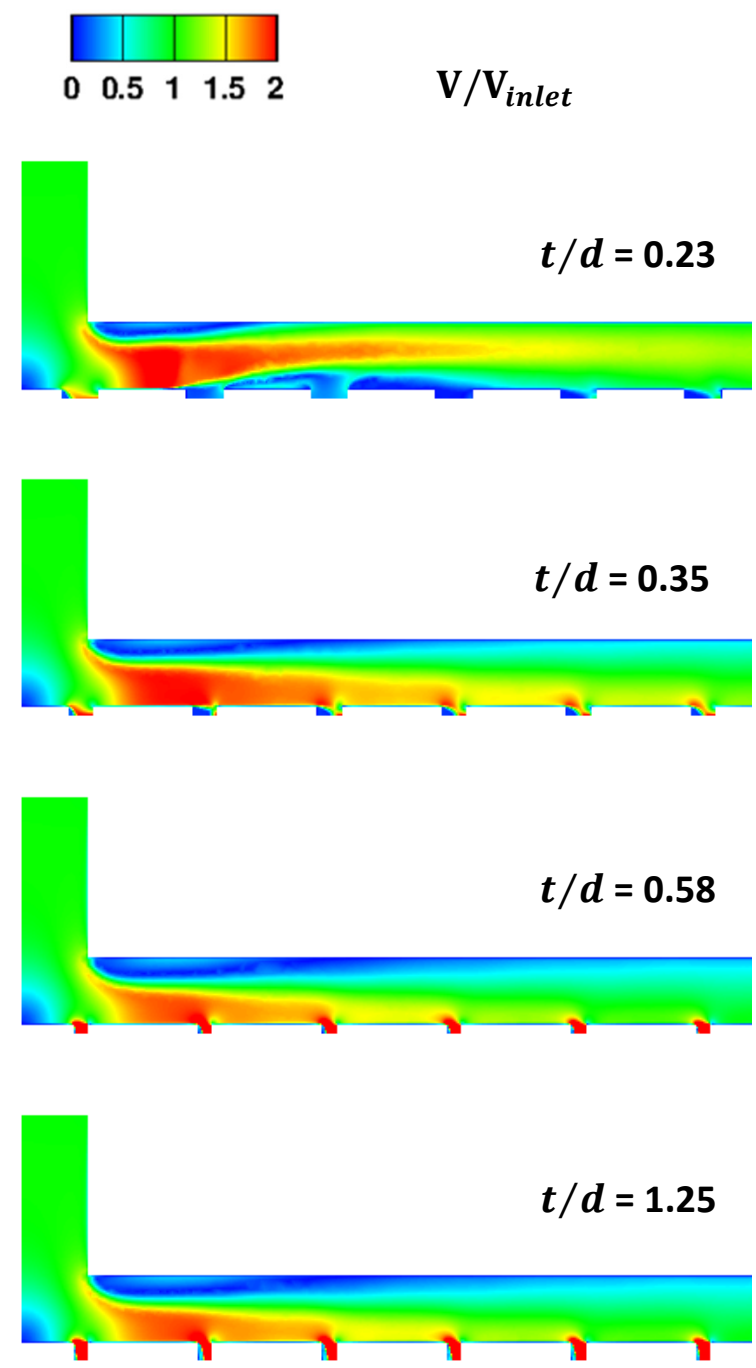
Fig. 13 Mass flow distribution for cases with $t / d$ ratio of 0.35

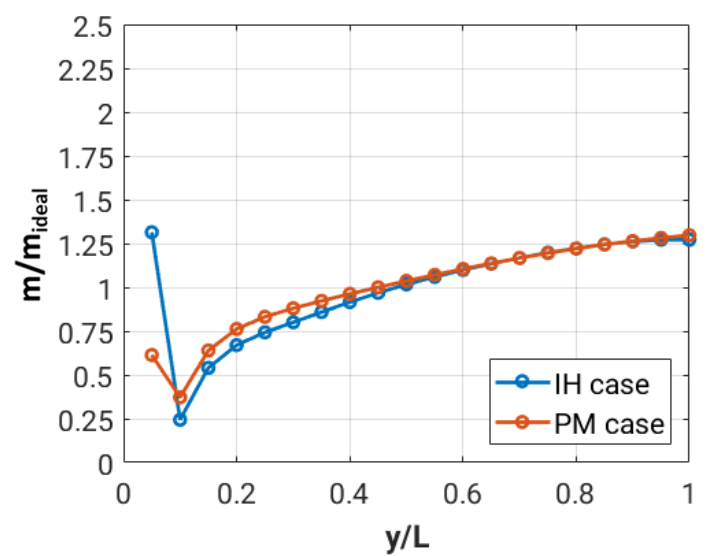

(1) $(A R)_{2}=2$

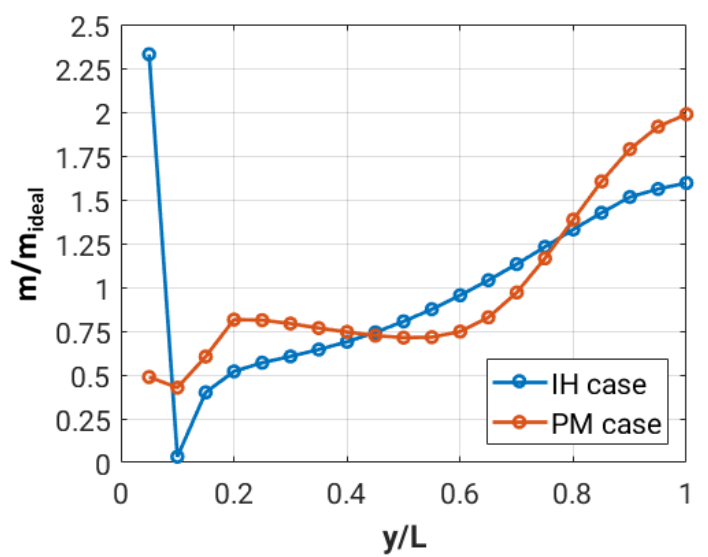

(2) $(A R)_{2}=1$ 
Fig. 14 Mass flow distribution with T-Shaped inlet

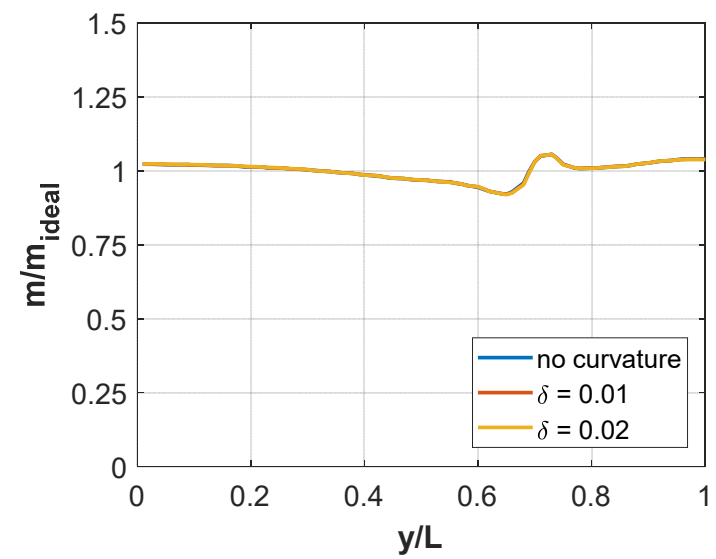

(1) Effect of curvature, IH, $(A R)_{2}=2$

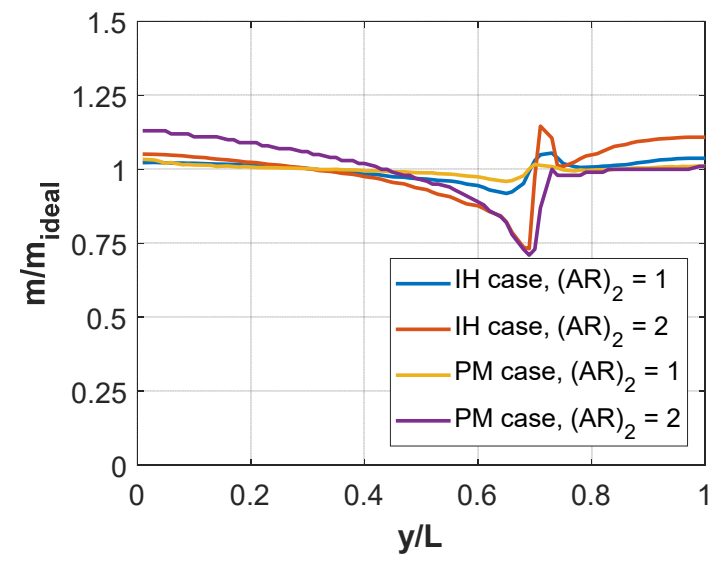

(2) Comparison with PM, $\delta=0.01$ 
Fig. 15 Normalized velocity magnitude contour plots for T-shaped inlet cases (IH)

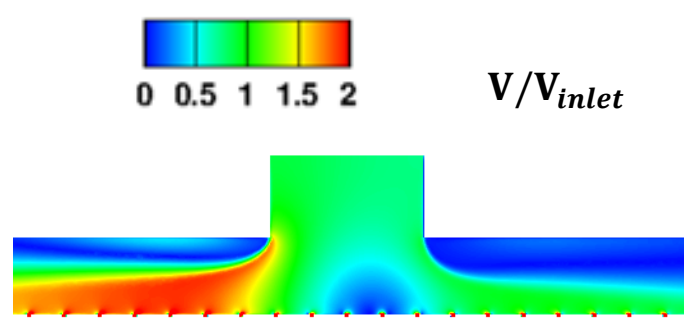

(1) No Curvature, $(A R)_{2}=2$

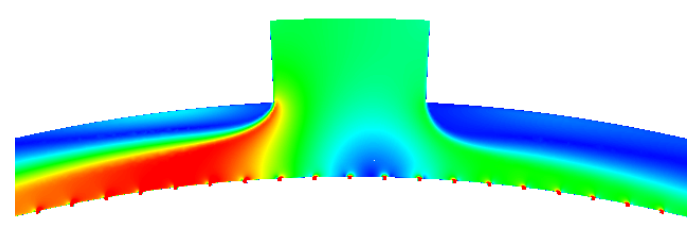

(2) High Curvature $(\delta=0.02),(A R)_{2}=2$

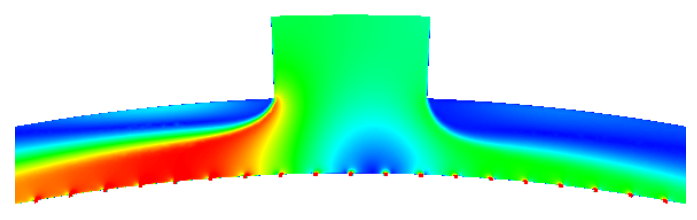

(3) Low Curvature $(\delta=0.01),(A R)_{2}=2$

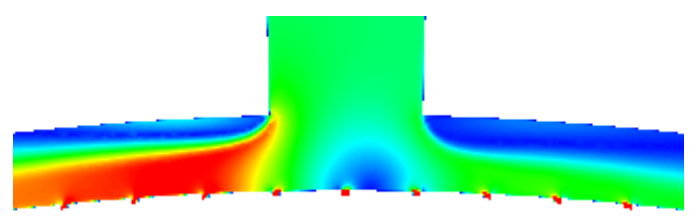

(4) Low Curvature $(\delta=0.01),(A R)_{2}=1$ 
Fig. 16 Normalized velocity magnitude contour plots for T-shaped inlet cases (PM)

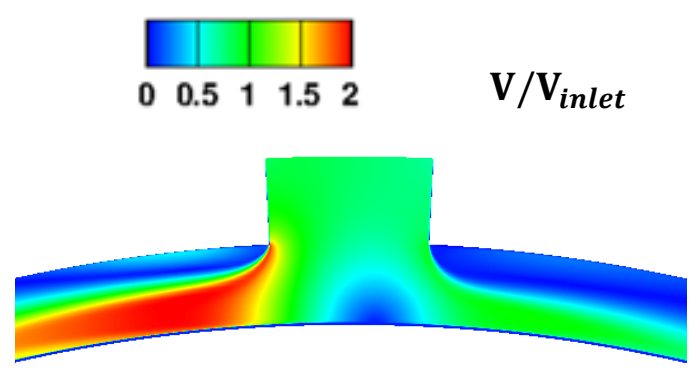

(1) High Curvature $(\delta=0.02),(A R)_{2}=2$

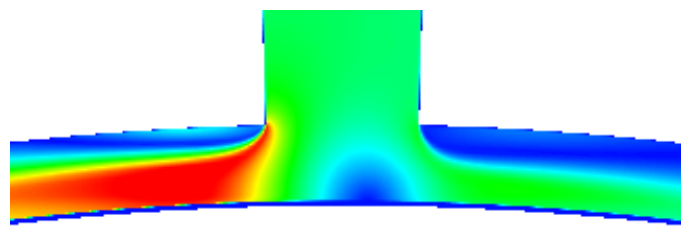

(2) Low Curvature $(\delta=0.01),(A R)_{2}=2$ 